\title{
Testing the use of cells equipped with solid polymer electrolytes for
}

\section{electro-disinfection.}

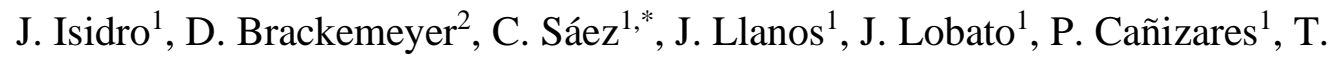

Matthée $^{2}$, M. A. Rodrigo ${ }^{1}$

${ }^{1}$ Chemical Engineering Department, Faculty of Chemical Sciences and Technologies, University of Castilla-La Mancha, Edificio Enrique Costa Novella. Campus Universitario s/n, 13005 Ciudad Real, Spain

${ }^{2}$ CONDIAS GmbH, Fraunhoferstraße 1b, 25524 Itzehoe- Germany

\section{Abstract}

This work focuses on disinfection of water using electrolysis with boron doped diamond (BDD) coatings and faces this challenge by comparing the performance of two different cells manufactured by CONDIAS GmbH (Izehoe, Germany): CONDIACELL ${ }^{\circledR}$ ECWP and CabECO cells. They are both equipped with diamond electrodes, but the mechanical design is completely different, varying not only by geometry but also by the flow conditions. ECWP is a flow-through cell with perforated electrodes while the CabECO cell is a zero-gap cell with a proton exchange membrane as a solid polymer electrolyte (SPE) separating the anode and cathode. At $0.02 \mathrm{Ah} \mathrm{dm}^{-3}$ both cells attain around 3-5 logs pathogen removal, but design and sizing parameters give an advantage to the CabECO: it can minimize the production of chlorates and perchlorates when operating in a singlepass mode, which becomes a really remarkable point. In this paper, we report tests in which we demonstrate this outstanding performance and we also explain the differences observed in the two cells operating with the same water. 
27 Electro-disinfection; chlorates; perchlorates; non-divided electrochemical cells; solid polymer electrolyte membrane cells; Boron Doped Diamond electrodes

29

Highlights

31

- Cell design is a decisive point for electro-disinfection with diamond electrodes

- Better performance of the zero-gap cell in electro-disinfection

- Around 3-4 logs pathogen removals in both cells.

34

- Chlorates and perchlorates avoided in zero-gap cells but not in flow-through cells

35

- Similar diamond coating can lead to very different disinfection efficiencies

36 
Disinfection of water is an issue with major relevance nowadays. It consists of the removal of pathogens from water to allow its safe use by humans. Although there are many different technologies, the most common deploy the addition or formation of oxidants that attack the pathogens such as chlorine and other chlorinated species. The real target behind the research carried out currently is to find a balance between the hazardousness of these oxidants for pathogens and humans: it is aimed to generate products extremely efficient in killing pathogens but with very low impact on human health. In attaining this goal, the electrochemical technology has experienced important advances in the recent years. Electrolysis is capable to transform ions contained in or added to water into powerful oxidants. Saline electrolysis is known to be very efficient and to have a very high technology readiness level, with many companies selling devices at very different scales, especially for saline swimming pools. However, the target now is to develop technology for the safe production of drinking water [1-8].

Diamond electrodes' commercialization at the turn of the century became a breakthrough in electrolytic technology. The very efficient mineralization of organics in wastewater and the high production of oxidants were the two most important advantages of that technology. The application in disinfection has shown promising results [9] but a very important drawback: the significant formation of chlorates and perchlorates, associated to the reactivity of chlorinated species on the surface of the diamond anodes [10-20]. In this case, hypochlorite is not the final product of the oxidation of chlorides but perchlorate. The challenges are to find a way in which the oxidation of chloride is stopped in the production of hypochlorite, while still producing other important oxidants such as ozone, peroxosulfates and peroxocarbonates. 
Typically, the electrode characteristics has been the most important target trying to determine if the $\mathrm{sp}^{3} / \mathrm{sp}^{2}$ ratio or the doping have a real influence on the progress of the undesired oxidation of hypochlorite [21]. Likewise, the promotion of other side reactions, like the oxidation of hydrogen peroxide, which stops the progress of the oxidation of hypochlorite to chlorate has been another strategy. However, what was found to be the most promising is the cell design, which this work is focused on.

Thus, using two commercial cells made by a European manufacturer (CONDIAS GmbH, Germany), the CONDIACELL ${ }^{\circledR}$ type ECWP (CC ECWP) and the CabECO cells, a comparison of the performance is going to be made in this work, trying to determine which of them have the best prospects for application in disinfection of drinking water. The first cell is a flow-through cell specially designed for a very efficient mineralization of wastewater polluted with low amounts of organics ("electrochemical wastewater polishing"), in which the treated liquid winds through a sequence of five perforated diamond anodes. The second cell is a new and special design made for the production of ozone in pure water (low conductivity) which has demonstrated an outstanding disinfection performance in the scope of the research made in an EU funded project which aimed to provide safe water to rural communities in sub-saharan Africa [14-16], although this CabECO cell is not recommended for the direct disinfection of highly-faecal polluted water because of electrode's fouling [14]. In this latter case, the electrolyte that allows to close the ionic circuit in the electrochemical cell is not the water but a solid polymer electrolyte (SPE), which is directly connecting the anode and the cathode. In turn, both electrodes are in direct contact with the treated water intended to be disinfected.

\section{Materials and Methods}


Electrochemical cells. Electro-disinfection was carried out in two different cells provided by CONDIAS GmbH (Itzehoe, Germany). The cells used DIACHEM ${ }^{\circledR}$ electrodes based on a perforated or mesh niobium substrate respectively (Figure 1).

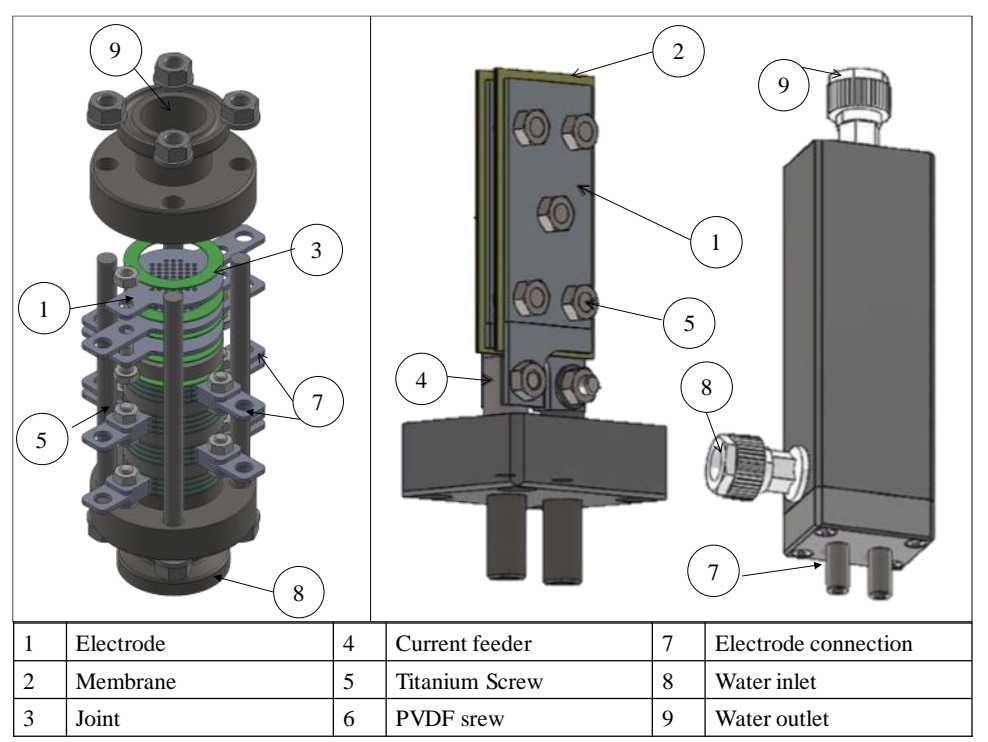

Figure 1. CONDIACELL ${ }^{\circledR}$ type ECWP (left) and CabECO (right) cells, with a simplified depiction of the CabECO's electrode stack.

The CONDIACELL ${ }^{\circledR}$ type ECWP system is an undivided cell equipped with five flowthrough diamond anodes (420 $\mathrm{mm}^{2}$ each) and stainless-steel cathodes. The CabECO cell is specially designed as a zero-gap cell to produce ozone in low-conductivity water. It is equipped with four DIACHEM ${ }^{\circledR}$ electrodes $\left(50 \times 24 \times 1.3 \mathrm{~mm}^{3}\right)$, which are assembled in two pairs with a NAFION ${ }^{\circledR}$ cation exchange membrane separating the anode and cathode and acting as the electrolyte. In this work, the cells were connected to the water reservoir by a peristaltic pump and powered by a Promax DC FA-376 power supply. A Keithley 2000 Multimeter was used to monitor the current and cell voltage.

Characterization. Ions concentrations were measured by ion chromatography using a Metrohm 930 Compact IC Flex coupled to a conductivity detector. A Metrosep A Supp 
7 column was used to determine anions, by passing through it a mobile phase consisted of $85: 15 \mathrm{v} / \mathrm{v} 3.6 \mathrm{mM} \mathrm{Na} 2 \mathrm{CO}_{3} /$ acetone with a flow rate of $0.8 \mathrm{~cm}^{3} \mathrm{~min}^{-1}$. The temperature of the oven was $45^{\circ} \mathrm{C}$ and $30^{\circ} \mathrm{C}$. The volume injection was $20 \mu \mathrm{L}$. Hypochlorite was analyzed by titration with $0.001 \mathrm{M} \mathrm{As}_{2} \mathrm{O}_{3}$ in $2 \mathrm{M} \mathrm{NaOH}$. Oxidants were determined iodometrically.

Water used in this work was collected at the inlet of the municipal Water Treatment Plant of Ciudad Real (Spain) and modified by the addition of strains of E. coli and Pseudomonas aeruginosa. Therefore, the disinfection of the surface water sample tested here was evaluated by these two indicators of pathogenicity. Microbiological tests conform to standard methods were used: UNE-EN ISO 9308-1:2014 and ISO 16266:2008 for the quantification of total coliforms and Pseudomonas aeruginosa, respectively. The initial concentrations of E. coli and P. aeruginosa attained were around $10^{4}$ and $10^{5} \mathrm{CFU}$, respectively. Further information is given as supplementary material.

\section{Results and Discussion}

Figure 2 shows the influence of the electric current charge passed on the removal of total coliforms and Pseudomonas aeruginosa obtained by the commercial electrochemical cells CONDIACELL ${ }^{\circledR}$ type EWCP and CabECO. In the CC EWCP the water to be disinfected acts as the electrolyte in the cell and thus, the cell voltage depends on the conductivity of this electrolyte. Typically, for most surface water, this conductivity is high enough to attain an efficient process and no salt addition is needed. However, with this direct electrochemical technology, conductivity is always a challenge and should be considered before the design of the disinfection process, because extremely low conductivities may prevent their use. Results shown in Figure 2 are attained in different tests carried out. All the tests were run in continuous mode with a single pass of the water 
through the cell. This means that after a transient response, data reported at the outlet corresponds to the concentration measured at the steady state. Regarding the current applied, the cells worked in galvanostatic mode by fixing a constant intensity ranging from 1 to 4 A. Additionally, flowrate was also varied from 90 to $300 \mathrm{~L} \mathrm{~h}-1$. Tables S. 1 and S.2 of supplementary material show the experimental condition used in each continuous test. In no case pH was controlled but relevant changes were not observed, and it ranged around the initial neutral $\mathrm{pH}$ value.
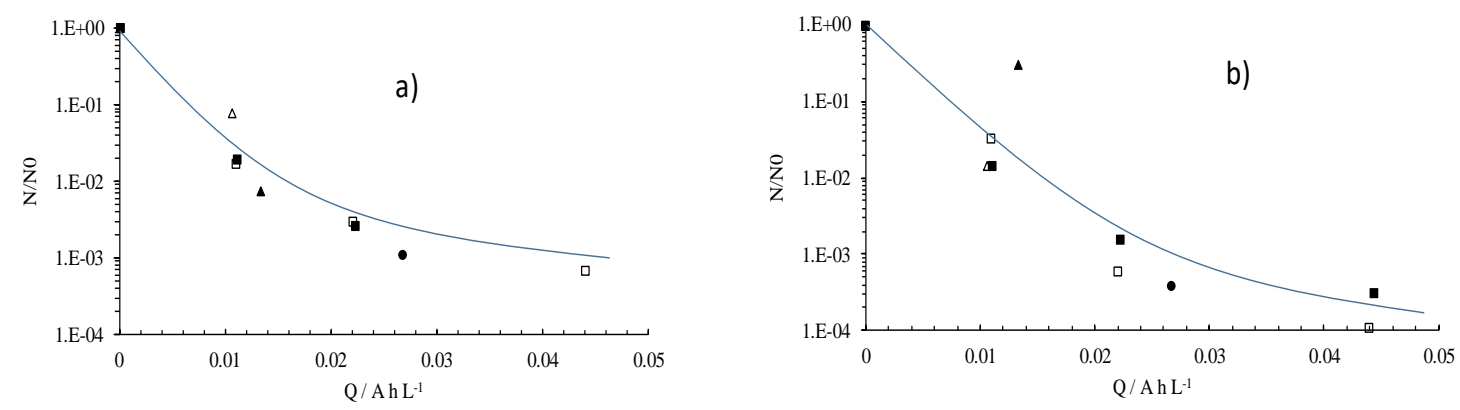

Figure 2. Disinfection attained by the CC ECWP (filled symbols) and CabECO (empty symbols) cells working in continuous mode: a) Total coliforms; b) Pseudomonas aeruginosa. $\square \square 90 \mathrm{~L} \mathrm{~h}^{-1} ; \triangle \triangle 300 \mathrm{~L} \mathrm{~h}^{-1}$ and $\bullet 150 \mathrm{~L} \mathrm{~h}^{-1}$.

As it can be observed, disinfection results obtained by CC ECWP are good and rather similar to those obtained by other non-divided electrochemical cells already existing in the market [17-20,22]. A 3-log decrease is attained in the concentration of both pathogens with charges as low as $0.02 \mathrm{Ah} \mathrm{L}^{-1}$. In fact, comparing them with results previously published [17, 19, 22], they seem to be around 1-log higher. Nevertheless, the comparison with the results of other works is not an easy task because this performance should not only depend on the cell but also on water composition, target pathogen and many other additional factors such as hydraulic conditions, applied current intensity or diamond coating properties. Anyway, the improved performance of the ECWP cell can be easily 
explained by the special electrode configuration of this cell that promotes high turbulence and, hence, a more efficient mass transport inside the cell. This confirms that electrolysis with diamond anodes is very efficient in the disinfection of water, allowing the removal of several $\log$ units of concentrations of both pathogens for very low electric current charges passed (below $0.05 \mathrm{Ah} \mathrm{L}^{-1}$ ). Additionally, this result also confirms the current charge applied as the key parameter to monitor the disinfection, because all results obtained lay over the same curve, despite each test was made at different current densities and flow rates.

The technology of the CabECO cell used is completely different and the electrolyte is not the treated water but a solid polymer electrolyte (SPE), which connects directly the anode and the cathode of the cell. Thus, with this zero-gap technology the conductivity of the water to be disinfected is no longer important in regard to power consumption and the electrochemical disinfection process can be used efficiently with water of very low conductivity. In fact, the higher the conductivity, the lesser is the efficiency due to scavenging reactions of either $\mathrm{O}_{3}$ or OH-radicals. In reality, these cells have been proposed as efficient ozone generators in pure water (Eq. 1) $[14,15,16]$. Working at these operation conditions, the membrane shows no signs of degradation and no compounds of the PFSA membrane have been detected in solution, confirming its high chemical resistance. Figure 2 also shows the removal of total coliforms and Pseudomonas aeruginosa attained with this cell. Again, a clear exponential decrease in the concentration of surviving pathogens is observed, regardless of the treated flow rate and applied intensity, confirming that the specific current passed is the primary operating parameter of the electro-disinfection process. Charge values applied are not very high (below $0.05 \mathrm{Ah} \mathrm{L}^{-1}$ ) and this means that disinfection is very efficient because even with power consumptions below $0.0123 \mathrm{kWh} \mathrm{m}^{-3}$, 5-log reductions of pathogen can be 
achieved. According to literature [14-17, 20], the cocktail of oxidants formed during the electrolysis, including ozone (which was the key oxidant in the design of zero gap cell) and persistent disinfectants such as hypochlorite and chloramines are mainly responsible for the good disinfection levels.

$$
\mathrm{O}_{2}+2(\mathrm{OH})^{\bullet} \rightarrow \mathrm{O}_{3}+\mathrm{H}_{2} \mathrm{O}
$$

In comparing the two cells evaluated in this work, important differences can be found in the efficiency of the electro-disinfection, being that the latter technology, with a SPE connecting the anode and the cathode, is more efficient than the flow-through cells technology that used. In fact, in this case at $0.02 \mathrm{Ah} \mathrm{L}^{-1}$, disinfection rates are almost or above 3-log units, which means at least 1-log more than the CC ECWP cell. In addition to the cell design, another relevant difference between the cells is the hydraulic residence time (HRT) and most particularly, the contact time of the fluid with the electrode, which is close to $0.21-0.69 \mathrm{~s}$ in the case of the CabECO and 0.16-0.52 s for the ECWP for the flowrate of 300 and $90 \mathrm{~L} \mathrm{~h}^{-1}$ respectively (Tables S.1 and S.2).

The results about disinfection are not surprising, in particular taking into account the recently published studies about electro-disinfection with diamond coatings [17-20,22]. However, they highlight the significance of the cell design in regards to the achieved high efficiencies in the disinfection, especially because of the outstanding results obtained by the zero-gap cell concept. There is also a very important point regarding disinfection with diamond anodes, which should not be avoided in the discussion: the production of chlorates and perchlorates during the electrolysis. It is far away from controversy that efficiency in the generation of oxidants during the electrolysis with diamond anodes is over the values that can be attained with other electrodes such as the MMO electrodes 
[23]. However, the occurrence of hazardous species has been identified as a major

200

201

202

203

204

205

206

207

208

209

210

211

212

213

214

215

216

217

218

219 drawback [16, 17, 19], which needs to be addressed.

This can be clearly seen in Figure 3, in which the speciation of chlorine during the electrolysis carried out with the ECWP cell is shown and where it can be seen that: 1) chlorate is formed as the main product and 2) perchlorate occurrence is observed. The data shown correspond to steady state and overall, the concentration of these two hazardous species is not high. In fact, the concentration of perchlorate was near the detection limit of the IC in use which explains the singular detection of perchlorates at only a moderate specific charge. This was achieved by the purposefully implemented strategy of continuous operation and single pass intended to minimize the production of the electrolysis by-products. However, results clearly point out that there is still room for improvement because the target is not simply the minimization but the total absence of both chlorinated products.
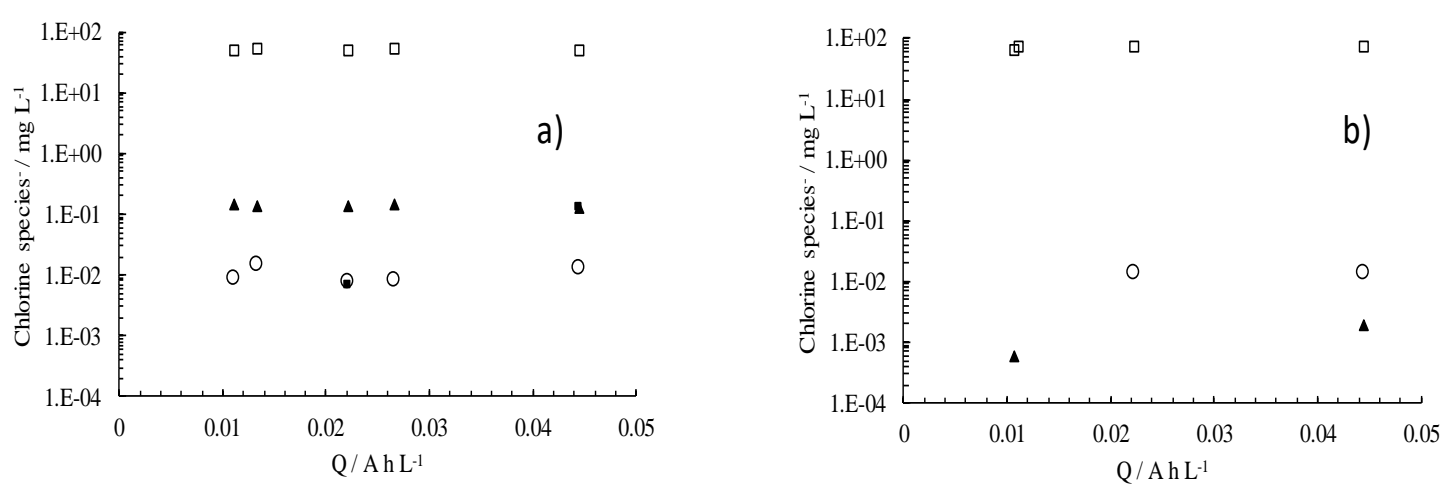

Figure 3. Speciation of chlorine during the electro-disinfection test carried out with a) the CC ECWP b) CabECO cells in continuous mode. $\square$ chloride; Ohypochlorite; $\boldsymbol{\Delta}$ chlorate; -perchlorate. positive influence on the prevention of the production of chlorates and perchlorates, 
because the most important electrolyte in the cell are not the dissolved salts but the proton

221

222

223

\section{2} exchange membrane between the anode and the cathode. This is confirmed in part $b$, which shows the results obtained in the CabECO cell. As expected, the concentration of chlorates is much lower (about two log difference: 0.15 vs. $0.002 \mathrm{mg} \mathrm{L}^{-1}$ ). This means that, in spite of its slightly higher HRT, the zero-gap configuration minimizes the risk of production of hazardous byproducts with concentrations that are negligible in the case of chlorate $\left(<2 \mu \mathrm{g} \mathrm{L}^{-1}\right)$ and even below the detection limit of the IC in the case of perchlorates.

Continuous mode and single pass through the cell were pointed out to minimize the impact of the production of chlorate and perchlorate and results obtained in this work confirm this assumption. Formation of perchlorate is a sequential process in which the formation of chlorine (and hypochlorite) are the first steps. It is important to maximize the yield of this low valent species and trying to avoid their further oxidation. If contact time between the hypochlorite containing solution and the electrode is very short, this further oxidation may be avoided.

In order to explore the mechanisms, it was decided to carry out additional treatments in discontinuous mode with the two cells. In discontinuous mode, the water is recirculated through the reactor several times and it is expected that the oxidation of hypochlorite to chlorates and perchlorates will be more important, as compared to the results obtained in continuous mode and single pass. This is because the production of these two species is promoted by the interaction of the hydroxyl radicals formed on the surface of the diamond anodes and the hypochlorite according to the previously described eqs. 2 and 3 . 
Figure 4 shows the performance of the electro-disinfection in discontinuous mode at current intensities within the range of 0.02-2.00 A carried out with the two cells. In

247 general terms the same conclusions can be drawn from the separate results obtained by 248 those two cells. Both cells show similar capacities for disinfection also in discontinuous 249 operation mode, with the removal of pathogens depending on the specific current passed. 250 Clearly the discontinuous mode seems to be less efficient in disinfection than the continuous mode. Thus, for the same electric charges, the removals obtained in discontinuous mode are at least one log below those obtained in continuous mode and a much higher applied charge is required in order to attain the same removal percentage. The different speciation of chlorine can help to explain the differences observed.
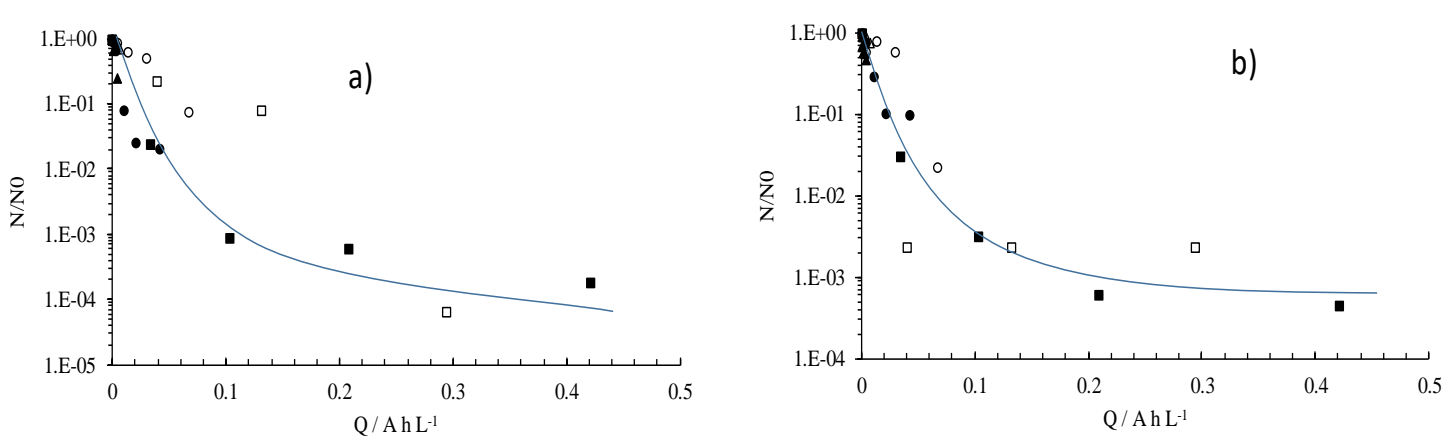

256

Figure 4. Removal of total coliforms (part a) and Pseudomonas aeruginosa (part b) with

CC ECWP cell (full symbols) and CabECO cell (empty symbols) in discontinuous mode:

The achieved reduction of microorganisms follows the expected trends in regards to specific charge dependency, though to explain the difference in efficiency between continuous and discontinuous mode, a closer look at the present chlorine species becomes important. As shown in Figure 5, the speciation is again rather different in the two cell concepts. The CC ECWP ${ }^{\circledR}$ cell produces concentrations of hazardous byproducts that are 
266 1-log higher than for the $\mathrm{CabECO}^{\circledR}$ cell. This confirms the outstanding performance of 267 the use of a solid polymer as electrolyte instead of the treated water.

268

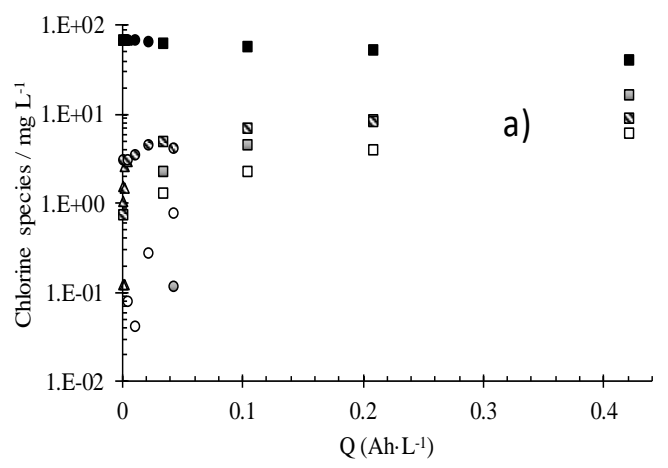

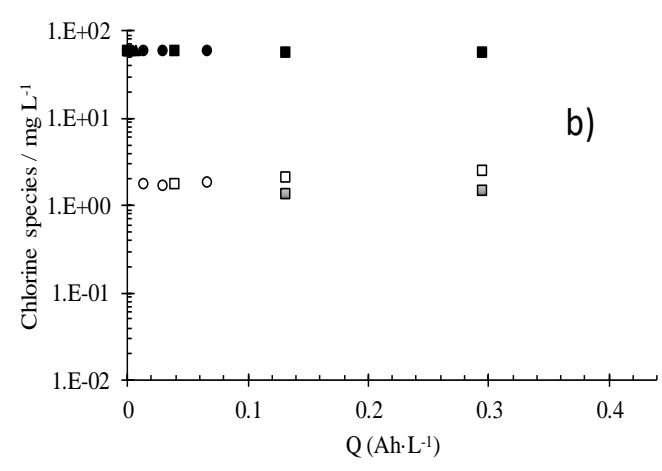

269

Figure 5. Speciation of chlorine with the two cells after operating in discontinuous mode. Chloride: full symbols; chlorate: empty symbols; perchlorate: degraded symbols; hypochlorite: dashed a) CC ECWP cell: $\boldsymbol{\Delta} 0.02 \mathrm{~A}$; 0.20 A; 2.00 A. b) CabECO cell:
$\Delta 0.02$
$\bullet 0.20 \mathrm{~A}$;
$2.00 \mathrm{~A}$

It is important to note, that the attained concentrations of chlorates and even perchlorates (Figure 5) are significantly higher in discontinuous mode than they are in continuous mode, regardless of the cell design. This confirms that not only the cell design, but more importantly the choice of operation mode can help prevent the formation of electrolysis byproducts in electrochemical disinfection. Concentrations are much higher in the case of the CC ECWP cell, confirming that the membrane-assembly concept used in the CabECO technology is suitable and advisable to prevent the formation of the chlorates and perchlorates. In order to be efficient, these cells have to be operated in continuous mode, because the repeated pass of the treated water through the cells favors the undesired reactions shown in eqs 1 and 2.

\section{Conclusions}


disinfection levels, confirming that electrolysis with diamond anodes is very effective. In

all cases, the higher the applied specific charge, the higher is the resulting level of

disinfection with up to 3 or 5-logs pathogen removal with electric charges applied as low

as $0.04 \mathrm{Ah} \mathrm{L}^{-1}$. Additionally, disinfection is more efficient in continuous than in

discontinuous operation mode and for a given electric charge passed, pathogen removals

are at least one log higher in continuous mode. The different speciation of chlorine can

help to explain the observed differences. An important outcome is that the use of zero-

gap electrolysis cells prevents the formation of highly oxidized chloro-species. Thus, with

CC ECWP chlorate concentrations were below $2 \mu \mathrm{g} \mathrm{L}^{-1}$ and the concentration of

perchlorate was negligible with continuous operation mode (single pass through the cell).

\section{Acknowledgments}

This research belongs to the SafeWaterAfrica project, funded by the European Union's

Horizon 2020 research and innovation program under grant agreement No 689925.

\section{References}

[1] I. Sirés, E. Brillas, M.A. Oturan, M.A. Rodrigo, M. Panizza, Electrochemical advanced oxidation processes: today and tomorrow. A review, Environmental Science and Pollution Research (2014).

[2] C.A. Martinez-Huitle, M.A. Rodrigo, I. Sires, O. Scialdone, Single and Coupled Electrochemical Processes and Reactors for the Abatement of Organic Water Pollutants: A Critical Review, Chemical Reviews 115 (2015) 13362-13407.

[3] R. Dewil, D. Mantzavinos, I. Poulios, M.A. Rodrigo, New perspectives for Advanced Oxidation Processes, J. Environ. Manage. 195 (2017) 93-99.

[4] S. Bebelis, K. Bouzek, A. Cornell, M.G.S. Ferreira, G.H. Kelsall, F. Lapicque, C.P. de Leon, M.A. Rodrigo, F.C. Walsh, Highlights during the development of electrochemical engineering, Chem. Eng. Res. Des. 91 (2013) 1998-2020. 
[5] C.A. Martinez-Huitle, E. Brillas, Electrochemical alternatives for drinking water disinfection, 318 Angewandte Chemie-International Edition 47 (2008) 1998-2005.

319 [6] J. Jeong, C. Kim, J. Yoon, The effect of electrode material on the generation of oxidants and 320 microbial inactivation in the electrochemical disinfection processes, Water Research 43 (2009) 321 895-901.

322 [7] M.I. Kerwick, S.M. Reddy, A.H.L. Chamberlain, D.M. Holt, Electrochemical disinfection, an environmentally acceptable method of drinking water disinfection?, Electrochimica Acta 50 (2005) 5270-5277.

[8] N. Ngwenya, E.J. Ncube, J. Parsons, Recent Advances in Drinking Water Disinfection: Successes and Challenges, Reviews of Environmental Contamination and Toxicology, Vol 222 222 (2013) 111-170.

[9] C. Bruguera-Casamada, I. Sires, E. Brillas, R.M. Araujo, Effect of electrogenerated hydroxyl radicals, active chlorine and organic matter on the electrochemical inactivation of Pseudomonas aeruginosa using BDD and dimensionally stable anodes, Separation and Purification Technology 178 (2017) 224-231.

[10] M.E.H. Bergmann, A.S. Koparal, T. lourtchouk, Electrochemical Advanced Oxidation Processes, Formation of Halogenate and Perhalogenate Species: A Critical Review, Critical Reviews in Environmental Science and Technology 44 (2014) 348-390.

[11] M.E.H. Bergmann, T. lourtchouk, W. Schmidt, J. Hartmann, M. Fischer, G. Nuesske, D. Gerngross, Laboratory- and technical-scale comparison of chlorate and perchlorate formation during drinking water electrolysis: a field study, Journal of Applied Electrochemistry 45 (2015) 765-778.

[12] H. Bergmann, A.T. Koparal, A.S. Koparal, F. Ehrig, The influence of products and byproducts obtained by drinking water electrolysis on microorganisms, Microchemical Journal 89 (2008) 98-107.

[13] M.E.H. Bergmann, J. Rollin, T. lourtchouk, The occurrence of perchlorate during drinking water electrolysis using BDD anodes, Electrochimica Acta 54 (2009) 2102-2107.

[14] J. Isidro, J. Llanos, C. Saez, J. Lobato, P. Canizares, M.A. Rodrigo, Pre-disinfection columns to improve the performance of the direct electro-disinfection of highly faecal-polluted surface water, Journal of Environmental Management 222 (2018) 135-140.

[15] J. Isidro, J. Llanos, C. Saez, D. Brackemeyer, P. Canizares, T. Matthee, M.A. Rodrigo, Can CabECO (R) technology be used for the disinfection of highly faecal-polluted surface water?, Chemosphere 209 (2018) 346-352.

\section{[16] A. De Battisti, P. Formaglio, S. Ferro, M. Al Aukidy, P. Verlicchi, Electrochemical} disinfection of groundwater for civil use - An example of an effective endogenous advanced oxidation process, Chemosphere 207 (2018) 101-109.

[17] Cano, P. Cañizares, C. Barrera, C. Sáez, M. A. Rodrigo, Use of low current densities in electrolyses with conductive-diamond electrochemical - Oxidation to disinfect treated wastewaters for reuse, Electrochemistry Communications 13 (2011) 1268-1270. [18] V. Schmalz, T. Dittmar, D. Haaken, E. Worch, Electrochemical disinfection of biologically treated wastewater from small treatment systems by using boron-doped diamond (BDD) electrodes - Contribution for direct reuse of domestic wastewater, Water Research 43 (2009) 5260-5266.

[19] S. Cotillas, E. Lacasa, C. Sáez, P. Cañizares, M. A. Rodrigo, Disinfection of urine by conductive-diamond electrochemical oxidation, Applied Catalysis B: Environmental, 2295 (2018) 63-70.

[20] M. Rajab, C. Heim, T. Letzel, J.E. Drewes, B. Helmreich, Electrochemical disinfection using boron-doped diamond electrode - The synergetic effects of in situ ozone and free chlorine generation, Chemosphere 121 (2015) 47-53. [21] S. Garcia-Segura, E. Vieira dos Santos, C.A. Martínez-Huitle, Role of sp3/sp2 ratio on the electrocatalytic properties of boron-doped diamond electrodes: A mini review, Electrochemistry Communications 59 (2015) 52-55. 
369 [22] A. Cano, C. Barrera, S. Cotillas, J. Llanos, P. Canizares, M.A. Rodrigo, Use of DiaCell 370 modules for the electro-disinfection of secondary-treated wastewater with diamond anodes, 371 Chem. Eng. J. 306 (2016) 433-440.

372 [23] C.E. Schaefer, C. Andaya, A. Urtiaga, Assessment of disinfection and by-product formation 373 during electrochemical treatment of surface water using a Ti//rO2 anode, Chem. Eng. J. 264 374 (2015) 411-416.

375 